\title{
- A crise paradigmática nas ciências de identificação de plantas e a valorização da etnobotânica
}

Gustavo Crizel Gomes ${ }^{1}$

Carlos Alberto Barbosa Medeiros²

João Carlos Costa Gomes ${ }^{3}$

Rosa Lia Barbieri ${ }^{4}$

\section{Resumo}

As ciências de identificação de plantas passam por uma crise paradigmática. Essa ciência teve seu início com a taxonomia de Lineu, baseada em características morfológicas, e teve a partir de Darwin a evolução como paradigma central. Desde o século XX, a genética e a fisiologia tornaram-se importantes na classificação dos seres vivos, com o uso da genética molecular na comparação de genomas. Mais recentemente, com avanços na biologia molecular e na bioinformática, mapeamentos genéticos e diagnósticos passaram a ser cada vez mais rápidos e precisos, provocando mudanças de nome (espécie) e família de algumas plantas, algumas vezes em poucos anos. Essas mudanças não afetaram populações tradicionais, agricultores familiares e mateiros, que continuam usando alguns caracteres tidos como secundários (estruturas vegetativas) para a sistemática clássica. Tais aspectos dendrológicos não só permitiram identificar as plantas com nomes populares, mas também a reconhecer seus usos, pois serviram de remédio, comida, uso na marcenaria, em construções e energéticos, entre outros. O que se propõe é a valorização desses conhecimentos em articulação com os novos paradigmas científicos, visto que ambos são complementares e contribuem, cada qual com suas peculiaridades, um com maior relevância e o outro com maior precisão, ao entendimento da flora arbórea, suas potencialidades e contribuições para a espécie humana.

Palavras-chave: Sistemática vegetal. Conhecimento tradicional. Filogenia.

\section{Introdução}

A biologia evolutiva é um ramo da ciência que se ocupa da origem e descendência de entidades biológicas (espécies, populações ou mesmo genes), bem como da sua modificação ao longo do tempo, ou seja, da sua evolução. É uma área multidisciplinar, na qual trabalham investigadores oriundos de várias áreas da ciência. O sistema de classificação dominante é conhecido como taxonomia lineana, que inclui conceitos como a estruturação em níveis hierárquicos e a nomenclatura binomial. Em plantas a atribuição de nomes científicos a organismos é regulada por acordos internacionais, como o Código Internacional de Nomenclatura Botânica (ICBN) (MCNEILL et al., 2007).

1 Embrapa Clima Temperado, bolsista de pós-doutorado. Pelotas, Rio Grande do Sul, Brasil. crizelgomes@gmail.com. BR 392, KM 78, Caixa Postal 403, Pelotas (RS), CEP 96010-971.

2 Embrapa Clima Temperado, pesquisador. Pelotas, Rio Grande do Sul, Brasil. carlos.medeiros@embrapa.br. BR 392 KM 78, Caixa Postal 403, Pelotas (RS), CEP 96010-971.

3 Embrapa Clima Temperado, pesquisador. Pelotas, Rio Grande do Sul, Brasil. costa.gomes@embrapa.br. BR 392 KM 78, Caixa Postal 403, Pelotas (RS), CEP 96010-971.

4 Embrapa Clima Temperado, pesquisadora. Pelotas, Rio Grande do Sul, Brasil. lia.barbieri@embrapa.br. BR 392 KM 78, Caixa Postal 403, Pelotas (RS), CEP 96010-971. 
A botânica sistemática é a ciência que estuda a diversidade de espécies vegetais, procurando organizá-las em grupos (táxons), baseando-se em hipóteses de relações evolutivas (estudos filogenéticos). A taxonomia vegetal é o ramo da ciência responsável pela ordenação e denominação das espécies vegetais, agrupando-as de acordo com o seu grau de semelhança, buscando determinar as relações de parentesco entre as espécies que hoje existem e seus ancestrais extintos (SOUZA; LORENZI, 2005). Cabe à taxonomia a descoberta, descrição e classificação das espécies e grupos de espécies, respeitando suas normas e princípios. Por muito tempo foram considerados apenas aspectos morfológicos de órgãos reprodutivos, basicamente das flores (considerando-se aqui as gimnospermas e as angiospermas).

O sistema de taxonomia vigente foi proposto por Lineu (LINNAEUS, 1735 apud STACE, 1991), em sua obra Systema naturae, a partir da ideia de divisão e denominação (divisio et denominatio), como forma de organizar os organismos vivos em táxons, considerando o ponto de partida da moderna nomenclatura binomial. Para as plantas, Lineu utilizou as características sexuais recentemente descobertas à época, lembrando que a morfologia das flores e das sementes apresenta um significado biológico específico. Animais e minerais, os outros dois reinos do sistema "animal-vegetal-mineral" por ele idealizado, foram organizados pela aparência externa. Seus estudos geraram grandes e inegáveis avanços no conhecimento e organização taxonômica dos seres vivos.

Porém, esses agrupamentos com base em características morfológicas sofreram várias alterações na busca de maior consistência entre a classificação e o princípio darwiniano de ascendência comum, pois Lineu classificava as espécies de seres vivos com o objetivo principal de facilitar a identificação e criar uma forma de arquivo nos herbários e nas coleções zoológicas, enquanto os modernos sistemas taxonômicos procuram refletir o princípio darwiniano de ancestralidade comum. Isso significa que se pretende agrupar as espécies por proximidade filogenética, isto é, relacionar as espécies pela sua proximidade genética, refletindo o grau de parentesco e ancestralidade.

A partir de Darwin (1859), a evolução passou a ser considerada como paradigma central da Biologia, respaldada por evidências da paleontologia sobre formas ancestrais e da embriologia sobre semelhanças nos primeiros estágios de vida. A classificação das plantas com base na morfologia dos seus órgãos reprodutores foi um tanto "desestruturada", baseada na teoria darwiniana de ancestralidade comum e evolução das espécies por meio da seleção natural, as relações evolutivas de parentesco (e não apenas as semelhanças/diferenças morfológicas de suas estruturas) são consideradas para a organização taxonômica dos organismos, adotando-se um ancestral comum para todos os níveis de agrupamentos monofiléticos.

\section{Avanços nas ciências de classificação de plantas}

Com os avanços da biologia molecular, os quais permitem a análise do genoma, é provável que as alterações taxonômicas continuem a ocorrer à medida que se caminha para um sistema de classificação baseado na semelhança genética e molecular em detrimento dos critérios morfológicos (LEE, 1995). A partir do século XX, a genética e a fisiologia tornaram-se importantes na classificação dos seres vivos, como o uso da genética molecular na comparação de genomas por meio de sequenciadores de DNA e eletroforese (MILLACH, 1998).

Recentemente surgiu a bioinformática, ramo da ciência multidisciplinar que, combinando diferentes informações disponíveis em bases de dados, produz resultados que vão desde mapeamentos genéticos até diagnósticos cada vez mais rápidos e precisos. Esses avanços nas pesquisas filogenéticas vêm trazendo mais instabilidade quanto ao posicionamento dos táxons e o surgimento de novas 
tecnologias e descobertas científicas, inclusive, ameaçam a perpetuação do sistema taxonômico baseado na morfologia de órgãos reprodutivos proposto por Lineu (SOUZA; LORENZI, 2005).

A cladística é um método de análise das relações evolutivas entre grupos de seres vivos, de modo a obter sua "genealogia". De acordo com a cladística, o reconhecimento de um táxon (incluindo famílias) baseia-se no seu histórico evolutivo, o que é refletido na formação de grupos monofiléticos, e não apenas na semelhança morfológica, o que pode ser mera coincidência (AMORIN, 1998). Chama-se monofilético a um clado (que pode ser um táxon, no sentido da taxonomia de Lineu), todas as espécies derivadas de uma única espécie ancestral, incluindo esse mesmo ancestral (FUNK; BROOKS, 1990).

Felizmente grande parte das famílias botânicas tradicionalmente descritas, mais representativas por conterem maior número de gêneros e espécies, como Poaceae, Asteraceae, Fabaceae e Myrtaceae, será mantida por formar grupos monofiléticos, permanecendo sem alterações em sua circunscrição. A maioria das mudanças ocorrerá naqueles grupos reconhecidos como superficiais, cuja instabilidade já foi motivo de divergências entre autores. Outro aspecto positivo é o fato de que, apesar de estarem passando por uma fase de muitas e rápidas mudanças, o que exige atualizações dos profissionais que tratam da biodiversidade vegetal, os avanços em estudos filogenéticos tendem a levar a classificação dos táxons do reino vegetal para a estabilidade, mesmo que exija tempo e despenda muito trabalho (SOUZA; LORENZI, 2005). Até este momento, o que se espera é que as novas técnicas e o empenho dos pesquisadores acelerem esse processo. Algumas publicações recentes destinadas à identificação de famílias botânicas como o "flowering plants of the neotropics" (SMITH et al., 2004) trouxeram as famílias botânicas divididas em mono e dicotiledôneas e em ordem alfabética, uma vez que, no momento, o posicionamento filogenético de muitas famílias não é estável.

De acordo com Kuhn (1975), a ciência passa por grandes crises paradigmáticas, que resultam nas revoluções científicas, e é exatamente nesses momentos de crise, quando o paradigma vigente é posto em cheque por anomalias e vai cedendo lugar a um novo paradigma, dito emergente, que o conhecimento científico tem avanços maiores (saltos) do que os gerados nos períodos de acumulação gradativa de conhecimento pela comunidade científica que professa o paradigma vigente, o qual é denominado ciência normal.

A botânica sistemática e a taxonomia vegetal passam neste momento por uma crise de paradigma, pois as relações evolutivas propostas por Darwin, as quais vêm sendo confirmadas em análises de DNA, contradizem, em alguns casos, o grau de aproximação de parentesco entre alguns táxons, que vinham sendo considerados pela comparação de estruturas reprodutivas, como proposto por Lineu. Cabe salientar que Lineu não considerou a evolução das espécies como resposta à seleção natural e suas proposições de organização taxonômica dos organismos que correspondiam ao paradigma criacionista vigente na época. Era desconhecido o fato de que as espécies derivavam umas das outras no tempo e no espaço como resposta ao acúmulo de mutações, seleção em distintos ambientes, surgimento de barreiras geográficas, mudanças ambientais e pressões ecológicas. Esses dois cientistas e suas teorias e proposições são complementares e deram algumas das maiores contribuições ao estudo dos seres vivos até então. Entretanto, com o passar do tempo, pode-se dizer que as afirmações de ambos foram confirmadas, mas existe outra parte delas que ainda necessita de melhor averiguação.

Lineu, mesmo desconhecendo a evolução, criou uma nomenclatura binomial válida e muito prática ainda hoje e, mesmo que algumas relações filogenéticas propostas com base em morfologia floral estejam sendo postas em cheque por estudos de genética molecular, as estruturas reprodutivas 
estão certamente menos sujeitas a mudanças em detrimento de necessidades adaptativas ao meio do que as vegetativas. Ainda hoje, ele é considerado o maior catalogador de espécies dos reinos animal e vegetal, sendo que muitas famílias, gêneros e espécies por ele catalogadas perpetuarão.

Darwin, apesar de a revolução que suas teorias de seleção natural e evolução das espécies causaram às ciências biológicas, valeu-se das ideias Lamarquistas, no que se refere à passagem dos caracteres adquiridos, pois não tinha o conhecimento dos genes e dos cromossomos, bem como da ocorrência de mutações, uma vez que as leis da hereditariedade só foram surgir em meados de 1850, nos experimentos do padre Mendel em cruzamentos com ervilha, outro grande colaborador ao entendimento da vida. Novas descobertas seguem acrescentando peças para a montagem do "quebra-cabeças" que nos leva a uma maior compreensão dos organismos que habitam (ou habitaram) o Planeta Terra e as relações por eles estabelecidas com outros seres bióticos e com o meio ambiente onde vivem ou viveram.

Com essa crise na botânica sistemática e taxonomia vegetal, algumas plantas mudaram de nome (espécie) e família, algumas vezes em poucos anos, e parece que tais atualizações tardarão a se concluir. Enquanto isso, populações tradicionais sempre identificaram e usaram as plantas de seus agroecossistemas para as mais diversas funções, pois enquanto a sistemática reorganiza-se, dependendo de técnicas ainda caras e pouco acessíveis (para os especialistas o prazo para a conclusão dos estudos em cladística não parece próximo), muitos moirões, caibros e piques ainda sustentam cercas, casas e galpões, e a comida e medicina retiradas das árvores nativas ajudam a manter as pessoas. Parece ser este o momento certo para valorização desse conhecimento, que vem sendo perdido com a morte das pessoas mais idosas, o êxodo rural e a falta de sucessão na agricultura familiar, com o desinteresse dos jovens em permanecerem "no campo" (CALDAS; ANJOS, 2005).

\section{Conhecimento tradicional, biodiversidade, etnociências e bioprospecção}

Conhecimento tradicional associado à biodiversidade é todo conhecimento, inovação ou prática, individual ou coletiva, de povos indígenas e comunidades locais, associados às propriedades, usos e características da diversidade biológica, inseridos dentro de contextos culturais próprios desses povos (SANTILLI, 2009). O conhecimento tradicional constitui-se de práticas, conhecimentos empíricos e costumes passados de pais para filhos e crenças das comunidades tradicionais que vivem em contato direto com a natureza; ou seja, é o resultado de um processo cumulativo, informal e de longo tempo de formação (GOMES, 2014). É crescente o reconhecimento da sociedade sobre a importância das comunidades tradicionais para a conservação da biodiversidade, uma vez que convivem em relação direta com a natureza, nomeando-a, classificando-a e dela apropriando-se para sua reprodução sociocultural e econômica (BARROS; SILVA, 2013).

Constitui-se, assim, patrimônio comum do grupo social e tem caráter difuso, pois não pertence a este ou aquele indivíduo, mas a toda comunidade, de maneira que todos que a ela pertençam devem receber os benefícios de seu uso ou exploração. Porém, não é dessa maneira que essa riqueza comunitária tem sido explorada por meio da bioprospecção (SANTILLI, 2003). Muitos desses recursos acabam sendo obtidos por apropriação dos conhecimentos tradicionais, os quais indicam material apropriado à pesquisa, encurtando a procura dos pesquisadores, ou seja, os conhecimentos tradicionais têm servido de indicadores para a pesquisa e para a geração de riqueza e poder sem que os verdadeiros proprietários do conhecimento recebam qualquer tipo de benefício (SANTILLI, 2009).

Os conhecimentos tradicionais vão desde técnicas de manejo de recursos naturais, métodos de caça e pesca, conhecimentos sobre os diversos ecossistemas, propriedades farmacêuticas, alimen- 
tícias e agrícolas de espécies até as próprias categorizações e classificações de espécies de flora e fauna utilizadas pelas populações tradicionais (SANTILLI, 2009). Diegues (2000) apresenta como características das populações tradicionais a interação com o meio ambiente por meio de técnicas de baixo impacto ambiental, a presença de instituições com legitimidade para fazer cumprir suas leis, além de liderança local, bem como a existência de formas equitativas de organização social.

Arruda (1998) acrescenta outras peculiaridades às comunidades tradicionais, tais como a intensa dependência da natureza e seu conhecimento e de seus ciclos. Tais peculiaridades refletem na elaboração de estratégias de uso e de manejo dos recursos naturais, na importância dada às simbologias, mitos e rituais associados à caça, pesca e atividades extrativistas e na reduzida acumulação de capital, havendo priorização da atividade de subsistência e a noção do território onde se reproduz. O conhecimento de populações locais sobre a natureza e seus processos é o objeto de pesquisa das etnociências, como a etnoecologia, a etnobiologia, a etnozoologia, a etnobotânica, entre outras.

A etnobiologia combina a realidade percebida pelo povo estudado com a visão do pesquisador que o estuda, ou seja, a visão êmica (percepção da etnia sobre os fenômenos naturais e sociais) com a visão ética (percepção do pesquisador) e faz uso de saberes das ciências naturais e sociais, propondo o resgate cultural, por meio do registro e documentação do conhecimento e informações sobre os usos tradicionais de plantas e animais, muitas vezes em processo de desaparecimento (DIAS et al., 2009).

A etnobotânica é o ramo da etnobiologia que se propõe a estudar as relações homem/plantas e pode ser definida como o enfoque científico multidisciplinar que tem como objeto de estudo as relações de apropriação e uso da biodiversidade vegetal nativa de uma determinada área geográfica por parte de um grupo social ali existente (ALBUQUERQUE, 2005).

Bioprospecção pode ser definida como o método ou forma de localizar, avaliar e explorar sistemática e legalmente a diversidade de vida existente em determinado local e tem como objetivo principal a busca de recursos genéticos e bioquímicos para fins comerciais (REID et al.,1993).

De acordo com estatísticas e estudos amplamente publicados na imprensa em geral, cerca de

$25 \%$ dos medicamentos existentes foram elaborados com ingredientes ativos extraídos de plantas, devendo ser registrada a relação de 119 substâncias químicas usadas regularmente na medicina em todo o mundo (FARNSWORTH, 1997), o que mostra a importância do uso da variedade da flora.

Dessa forma, a matéria-prima, no caso a diversidade de vida, passou a ter maior valor de mercado e consequentemente cada vez mais atenção dos países detentores, o que aliado à crescente consciência da valorização da biodiversidade fez com que se buscassem regras para a sua exploração. Assim, surgiu em âmbito planetário uma nova forma de exploração de produtos, os recursos naturais biológicos, surgindo então a bioprospecção.

\section{Métodos científicos e empíricos na identificação de plantas e seus usos}

A sistemática vegetal mostrou-se até então uma ciência cartesiana, baseada praticamente no número e posição de peças florais, que só legitima a identificação de táxons por meio de suas chaves analíticas (com base em morfologia de estruturas reprodutivas, principalmente flores) e praticamente desconsidera todo o restante do "corpo" das plantas. Por outro lado, nos métodos tradicionalmente usados para a identificação de plantas por agricultores, indígenas e mateiros, as características mais importantes são as estruturas vegetativas.

O rigor científico na sistemática vegetal, que reflete o paradigma vigente na ciência de modo geral, desencorajou por algum tempo tentativas de identificação ou classificação não baseadas em aspectos morfológicos de órgãos reprodutivos por desconsiderar seu "valor científico." Assim, até 
relativamente pouco tempo, não havia publicações destinadas à identificação de plantas em nível local com base em características morfológicas vegetativas, que auxiliariam os leigos em taxonomia e sistemática e, até mesmo, especialistas a identificarem a biodiversidade vegetal. Apenas recentemente começaram a surgir publicações para identificação de espécies da flora de uma determinada região com base em aspectos vegetativos (REJMÁNEK; BREWER, 2001).

Durante décadas os agentes da ciência moderna foram às áreas rurais para ensinar, modernizar, aperfeiçoar ou desenvolver as formas de identificação e aproveitamento dos recursos naturais, sem considerar que as famílias de agricultores são atores sociais, capazes de gerar e transmitir conhecimentos e de inventar, inovar e experimentar durante o processo de obtenção de bens e serviços da natureza. 0 fato de que os agricultores pertencem a culturas com uma longa história de interação com o meio ambiente em que vivem não foi levado em consideração. Assim, os herdeiros da ciência moderna transmitiram, unidirecional e verticalmente, conhecimentos, técnicas e experiências a um setor considerado atrasado, primitivo e subdesenvolvido (TOLEDO, 1997), porém somente a articulação entre conhecimento científico e saberes tradicionais pode produzir outro nível de conhecimento a ser compartilhado por agricultores e cientistas (GOMES; MEDEIROS, 2009).

O estudo da taxonomia vegetal baseado na morfologia de flores, frutos e sementes é bastante complexo. Os inúmeros termos usados na caracterização das estruturas reprodutivas e seus órgãos, possibilitando a distinção e agrupamento das espécies em famílias e gêneros, exigem algum tempo e muita dedicação para a compreensão e aprendizado do método proposto, o que, via de regra, está muito distante da compreensão e do nível de estudos acadêmicos de agentes de assistência técnica, extensão rural e agentes de desenvolvimento, e é um tema muito mais complexo para produtores rurais, agricultores familiares, comunidades indígenas e quilombolas, entre outros.

À complexidade do estudo da morfologia das estruturas reprodutivas soma-se a indisponibilidade de material bibliográfico, dificultando ainda mais o estudo da botânica sistemática. Para identificação das famílias botânicas, gêneros e espécies são necessárias as chaves analíticas. Porém, desde o surgimento da obra de Martius (1824), idealizada e editada em sua maior parte por Karl Friederich Philipp von Martius, entre os anos de 1840 e 1906, ainda que muitos trabalhos tenham sido realizados, dada a grande diversidade que o Brasil possui, ainda há muito o que se estudar.

Apenas recentemente foram publicadas obras sobre botânica sistemática com chaves e descrições morfológicas de todas as famílias botânicas que compõem a flora brasileira (SOUZA; LORENZI, 2005, 2012). Para a identificação de gêneros e espécies, a carência de material bibliográfico publicado em língua portuguesa é ainda maior e, até o surgimento e socialização do acesso à internet, mesmo publicações em língua estrangeira eram de difícil acesso.

Não cabe questionar a legitimidade e as imensas contribuições que os estudos da morfologia de estruturas reprodutivas trouxeram para o entendimento e agrupamento taxonômico das espécies de plantas que compõem a biodiversidade vegetal que existe ou já existiu no Planeta Terra. A riqueza de espécies vegetais torna um grande desafio a correta identificação e organização hierárquica com base em relações evolutivas.

Por outro lado, os conhecimentos tradicionais, empíricos, de populações locais, como os que foram acumulados pelos agricultores familiares da Serra dos Tapes, possibilitaram corretas associações (evolutivas) de "parentesco" entre espécies, relacionadas por seus nomes populares (também ditos vulgares, comuns ou vernaculares), como é o caso das diversas espécies de canelas (sebo, merda, guaicá, lageana, imbuia...), capororocas (de-folha-grande, de-folha-pequena, vermelha...) ou aroeiras (mansa, braba, cinzenta, salsa...), entre tantas outras (GOMES, 2014). Muitas dessas relações filogenéticas 
foram recentemente comprovadas pelas novas e modernas tecnologias (SOUZA; LORENZI, 2005). Esses conhecimentos foram gerados e mantidos empiricamente, com base em aspectos morfológicos de outras partes das plantas, que certamente não suas flores, pois para a maioria das espécies, essas estão presentes por um curto período de tempo por ano e muitas vezes são imperceptíveis, como no caso de indivíduos adultos de espécies de grande porte, e diminutas.

$\mathrm{Na}$ identificação empírica e tradicional das espécies são considerados alguns caracteres tidos como secundários para a sistemática clássica, como cor, estrutura e aspecto da casca, porte, forma da copa e do tronco, presença de acúleos e espinhos, de látex e outras exsudações, bem como de odores peculiares em folhas, casca e outras partes vegetais, sendo exatamente esse tipo de caracteres que permitem a agricultores, mateiros e outros leigos em botânica sistemática reconhecerem as principais essências nativas de uma determinada área geográfica (MARCHIORI, 1995).

Tais aspectos dendrológicos não só permitiram identificar as plantas com nomes populares, mas também a reconhecer seus usos, pois serviram de remédio, comida, para fins de marcenaria, construções, energéticos, entre outros, sendo que a maioria delas tem pelo menos um uso reconhecido pelo conhecimento tradicional e facilitaram ou até foram imprescindíveis para a sobrevivência das pessoas e manutenção de sua cultura.

Fato de grande relevância quanto às estratégias de apropriação da biodiversidade arbórea é que muitos nomes populares atribuídos às espécies (com diferentes raízes etimológicas) remetem a características morfológicas ou sensoriais específicas, como carne-de-vaca (referindo-se à cor do xilema), canela-merda (odor do xilema), capororoca, (do tupi-guarani caá pororoca "árvore que estala", referindo-se a características físicas da madeira), mamica-de-cadela (referindo-se aos acúleos presentes no fuste). Outros nomes populares indicam usos historicamente associados às espécies, como chá-de-bugre, espinheira-santa e sete-sangrias (todas com propriedades medicinais atribuídas, sendo a última considerada depurativa), açoita-cavalo (de cujos ramos se confeccionavam açoites). Ainda alguns nomes remetem a relações ecológicas, por exemplo, araticum, (do tupi-guarani ará ticu, "comida de arara") e sarandi (cuja etimologia da palavra em tupi-guarani refere-se a árvores de beira de rio) (GOMES, 2014).

Cabe salientar que algumas vezes a nomenclatura popular pode levar a confusões, visto que algumas espécies, por terem características ou comportamento semelhantes, levaram os mesmos nomes (MARCHIORI, 1995), como no caso dos sarandis (nome atribuído a diversas espécies de ocorrência ripária, flexíveis e bastante ramificadas, adaptadas a suportar a força das águas nas enchentes, porém distantes filogeneticamente) e sucarás (palavra de provável origem indígena referente à presença de espinhos no tronco e também atribuídas a diferentes espécies, pertencentes a famílias distintas). Como existem diversas espécies às quais são atribuídos os mesmos nomes, uma mesma espécie pode receber nomes distintos por questões regionais ou até dentro de uma região geográfica, dependendo de fatores culturais ou simplesmente pessoais.

Algumas vezes os nomes populares são compostos e o segundo nome faz referência a determinada característica morfológica específica que serve para distinguir espécies aparentadas filogeneticamente e morfologicamente muito semelhantes, como é o caso de branquilho leiteiro (lactescente, diferindo-o dos demais branquilhos), tarumã-de-espinho (distinguindo esta das demais espécies de tarumãs, todas inermes), araticum liso e araticum rugoso (aludindo ao aspecto da película que envolve os sincarpos) (GOMES, 2014).

Não se deve deixar de admitir e salientar que a nomenclatura popular e a identificação taxonômica de árvores a partir de aspectos dendrológicos não têm a mesma precisão e não podem substituir 
seus nomes científicos e a organização filogenética das espécies em táxons (seja com base em DNA ou em morfologia floral) para estudos mais exigentes quanto ao rigor científico. Porém, a validade e a importância desses conhecimentos muitíssimo têm a contribuir (e contribuem) à identificação de árvores e consequente manejo de agroecossistemas.

\section{Considerações finais}

Propõe-se a consideração e o reconhecimento do valor científico dos saberes locais, partindo da premissa de que o novo paradigma científico, denominado holístico, sistêmico ou ecológico, como proposto por Capra (1996), no qual se inserem os enfoques científicos da agroecologia, etnobotânica e outras ciências, incorpora em sua base epistemológica a complexidade, a dúvida e a incerteza e pretende ser multi, inter ou transdisciplinar, reconhecendo a validade dos saberes tradicionais (GOMES; MEDEIROS, 2009).

Tendo em vista que árvores são organismos de grande porte e bastante peculiares, parece que aspectos palpáveis e visíveis a olho nu, cheiros e gostos, entre outras características são válidos para que um grande número de pessoas interessadas (agricultores, técnicos, acadêmicos, etc) realizem a identificação eficaz das espécies em uma dada região. Obviamente chegar a identificação desse tipo é insuficiente para o avanço científico, devendo-se ainda considerar que seu uso restrinja-se a uma área geográfica bem específica, dadas diferenças de percepções em diferentes contextos.

O conhecimento local associado também é de extrema importância em processos em que os saberes empíricos sobre as espécies e seus usos sejam complementares ao conhecimento científico, visto que ambos estão sujeitos a erros e contribuem cada qual com suas peculiaridades, um com maior relevância e o outro com maior precisão (BARRIOS; TREJO, 2003) ao entendimento da flora arbórea, suas potencialidades e contribuições para a espécie humana.

\section{Abstract}

The plant identification sciences are facing a paradigm crisis. This science began with Linnaeus taxonomy, based on morphological characteristics, and its central paradigm is evolution, brought by Darwin. Since the twentieth century, genetics and physiology have become important for the classification of living beings by using molecular genetics in the comparison of genomes. More recently, due to advances in molecular biology and bioinformatics, the genetic mapping and diagnostics have become faster and more accurate, resulting in changes of name (species) and family of some plants, sometimes those changes happen in a few years. These changes did not affect traditional populations, family farmers and foresters, who continue using some characters taken as secondary (vegetative structures) to the classical systematic. Dendrological aspects not only made it possible to identify plants with popular names, but also to recognize their uses, since they were used as medicine, food, in carpentry, construction and energy, among others. We propose the valorization of this knowledge in conjunction with the new scientific paradigms, as both of them are complementary and contribute, each with its own peculiarities, one with greater relevance and the other with greater precision, to the understanding of arboreal flora, its potential and contributions to the human species.

Keywords: Sistematic Botany. Tradicional Knowledge. Phylogeny. 


\section{Referências}

ALBUQUERQUE, U. P. Introdução a Etnobotânica. 2. ed. Rio de Janeiro: Interciência, 2005.

AMORIN, D. S. Elementos básicos de sistemática filogenética. 2. ed. Ribeirão Preto: Holos, 1998.

ARRUDA, R. S. V. Populações tradicionais e a proteção dos recursos naturais em Unidades de Conservação. In: CONGRESSO BRASILEIRO DE UNIDADES DE CONSERVAÇÃO, 1997, Curitiba. Anais... Curitiba, 1998, v. 1, p. 351-367.

BARRIOS, E.; TREJO, M. T. Implications of local soil knowledge for integrated soil management. Geoderma, Tegucigalpa, v. 111, n. 3, p. 217-231, 2003.

BARROS, F. B.; SILVA, L. M. S. Agroecologia e aproximações de saberes como essência do desenvolvimento sustentável nos trópicos. In: GOMES, J. C. C.; ASSIS, W. S. de. Agroecologia: princípios e reflexões conceituais. Brasília: Embrapa. 2013. p. 109-144.

CALDAS, N. V.; ANJOS, F. S. O futuro ameaçado: o mundo rural face aos desafios da masculinização, do envelhecimento e da desagrarização. Ensaios FEE, Porto Alegre, v. 26, n. 1, p. 661-694, jun. 2005.

CAPRA, F. A teia da vida, uma nova compreensão científica dos sistemas vivos. São Paulo: Cultrix. 1996.

DARWIN, C. (1859). A origem das espécies. São Paulo: Editora Martin Claret, (2004).

DIAS, T. A. B.; FREITAS, F. O.; ZARUR, S. B. B. C.; BUSTAMANTE, P. G. Etnobiologia e conservação da agrobiodiversidade: pesquisa e inclusão dos povos indígenas craô, caiabi e iaualapiti. In: SOUSA, I. S. F.; CABRAL, J. R. F. (Org.). Ciência como instrumento de inclusão social. Brasília: Embrapa, 2009. p. 83-108.

DIEGUES, A. C. Etnoconservação. São Paulo: Hucitec/Nupaub, 2000.

FARNSWORTH, N. Testando plantas para novos remédios. In: WILSON, E. O. Biodiversidade. Rio de Janeiro: Editora Nova Fronteira, 1997. p.107-125.

FUNK, V. A.; BROOKS, D. R. Phylogenetic systematics. Washington: Smithsonian Institution Press, 1990.

GOMES, G. C. As árvores nativas e o saber local como contribuição à sustentabilidade de agroecossistemas familiares na Serra dos Tapes (RS). 2014. 352f. Tese (Doutorado), Universidade Federal de Pelotas, Pelotas, 2014.

GOMES, J. C. C.; MEDEIROS, C. A. B. Bases epistemológicas para a ação e pesquisa em agroecologia: da ciência eficiente à ciência relevante. In: SOUSA, I. S. F.; CABRAL, J. R. F. Ciência como instrumento de inclusão social. Brasília: Embrapa, 2009. p. 249-275.

KUHN, T. S. A Estrutura das Revoluções Cientificas. São Paulo: Perspectiva, 1975.

LEE, M. DNA markers and plant breeding programs. Advances in Agronomy, New York, v. 55. p. 265-343. 1995. 
LINNAEUS, C. Systema naturae per regna tria naturae, secundum classes, ordines, genera, species, cum characteribus differentiis, synonymis, locis. Editio décima, 1735.

MARCHIORI, J. N. C. Elementos de dendrologia. Santa Maria: Ed. UFSM, 1995.

MARTIUS, C. P. F. Tabula Geographica Brsiliae et terrarium adjacentium. Tabula Geographica quinque províncias florae Brasiliensis illustrans. In: MARTIUS, C. P. F.; EICHLER, A. G.; URBAN, I. Flora Brasiliensis, Monachii et Lipsiae, v. 1, p. 1, fasc 21. 1824.

MCNEILL, J., BARRIE, F. R.; BURDET, H. M.; DEMOULIN, V.; HAWKSWORTH, D. L.; MARHOLD, K.; NICOLSON, D. H.; PRADO, J.; SILVA, P. C.; SKOG, J. E.; WIERSEMA, J. H.; TURLAND, N. J. Código Internacional de Nomenclatura Botânica. Tradução: Carlos Eduardo de Mattos Bicudo; Jefferson Prado. São Paulo: Rima Editora. 2007.

MILLACH. S. C. K. Marcadores de DNA em plantas. Porto Alegre: UFRGS. 1998.

REID, W. V.; LAIRD, S. A.; MEYER, C. A.; GAMEZ, R.; SITTENFELD, A. Prospección de la biodiversidad. San José: World Resources Institute. 1993.

REJMÁNEK, M.; BREWER, S. W. Vegetative Identification of tropical Woody plants: state of the art and annotated bibliography. Biotropica, São Paulo, v. 3, n. 2, p. 214-228, 2001.

SANTILLI, J. Biodiversidade e conhecimentos tradicionais associados: novos avanços e impasses na criação de regimes legais de proteção. Revista de Direito Ambiental, São Paulo, v. 8, n. 29, p. 83102, jan.- mar., 2003.

SANTILLI, J. Agrobiodiversidade e direitos dos agricultores. São Paulo: Peirópollis, 2009.

SMITH N.; MORI, S. A.; HENDERSON A.; STEVENSON, D. W.; HEALD, S. V. Flowering plants of the neotropics. New Jersey: Princeton, 2004.

SOUZA, V. C.; LORENZI, H. Botânica sistemática: guia ilustrado para identificação das famílias de Angiospermas da flora brasileira, baseado em APG II. Nova Odessa: Instituto Plantarum, 2005.

SOUZA, V. C.; LORENZI, H. Botânica sistemática: guia ilustrado para identificação das famílias de Angiospermas da flora brasileira, baseado em APG III. 3. ed. Nova Odessa: Instituto Plantarum, 2012.

STACE, C. A. Plant taxonomy and biosystematics. Cambridge. Cambridge University Press, 1991.

TOLEDO, V. M. Qué es la etnoecologia? Orígenes, alcance e implicaciones de una disciplina en cresciente ascenso. In: AMOR, R. Nacionalismo - internacionalismo, una visión dialéctica. Sevilla: Muñoz Moya, 1997. p.159-181.

Histórico editorial:

Submetido em: 24/09/2015

Aceito em: 28/01/2016 
Como citar:

ABNT

GOMES, G. C.; MEDEIROS, C. A. B.; GOMES, J. C. C.; BARBIERI, R. L. A crise paradigmática nas ciências de identificação de plantas e a valorização da etnobotânica. Revista Agrogeoambiental, Pouso Alegre, v. 9, n. 1, p.115-125, jan./mar. 2017. DOI: http://dx.doi.org/10.18406/2316-1817v9n12017896

APA

GOMES, G. C., MEDEIROS, C. A. B., GOMES, J. C. C. \& BARBIERI, R. L. (2017). A crise paradigmática nas ciências de identificação de plantas e a valorização da etnobotânica. Revista Agrogeoambiental, 9 (1), 115-125. DOI: http://dx.doi.org/10.18406/2316-1817v9n12017896

$\underline{I S O}$

GOMES, G. C.; MEDEIROS, C. A. B.; GOMES, J. C. C. e BARBIERI, R. L. A crise paradigmática nas ciências de identificação de plantas e a valorização da etnobotânica. Revista Agrogeoambiental. 2017, vol. 9, n. 1, pp. 115-125. elSSN 2316-1817. DOI: http://dx.doi.org/10.18406/2316-1817v9n12017896

\section{VANCOUVER}

Gomes GC, Medeiros CAB, Gomes JCC, Barbieri RL. A crise paradigmática nas ciências de identificação de plantas e a valorização da etnobotânica. Rev agrogeoambiental. 2017 jan/mar; 9(1): 115-125. DOI: http://dx.doi.org/10.18406/2316-1817v9n12017896 